\title{
Arsenic induced complete remission in a refractory T-ALL patient with a distinct T-cell clonal evolution without molecular complete remission: A case report
}

\author{
SUIJING WU ${ }^{1 *}$, LING XU $^{2 *}$, XIN HUANG $^{1}$, SUXIA GENG $^{1}$, YAN XU $^{2,3}$, SHAOHUA CHEN $^{2}$, \\ LIJIAN YANG ${ }^{2}$, XIULI WU ${ }^{2}$, JANYU WENG ${ }^{1}, \mathrm{XIN} \mathrm{DU}^{1}$ and YANGQIU $\mathrm{LI}^{2,3}$, \\ ${ }^{1}$ Department of Hematology, Guangdong General Hospital, Guangdong Academy of Medical Sciences, Guangzhou, \\ Guangdong 510080; ${ }^{2}$ Institute of Hematology, Jinan University; ${ }^{3}$ Key Laboratory for Regenerative Medicine, \\ Ministry of Education, Jinan University, Guangzhou, Guangdong 510632, P.R. China
}

Received March 24, 2015; Accepted April 15, 2016

DOI: $10.3892 / 01.2016 .4529$

\begin{abstract}
Currently, arsenic trioxide therapy is widely used for the treatment of acute promyelocytic leukemia (APL), relapsed and refractory adult T-cell leukemia/lymphoma and myelodysplastic syndrome. Regarding the broad antitumor activity of arsenic, certain studies have been undertaken to test its efficacy in treating acute T-cell lymphoblastic leukemia (T-ALL) cell lines and patients; however, to the best of our knowledge, no reports document that arsenic is able to induce the remission of T-ALL patients. The present study reports the case of young male patient diagnosed with T-ALL, with no significant response to common chemotherapy regimens, who finally achieved complete remission without minimal residual disease (as detected by flow cytometry) due to arsenic
\end{abstract}

Correspondence to: Professor $\mathrm{Xin} \mathrm{Du}$, Department of Hematology, Guangdong General Hospital, Guangdong Academy of Medical Sciences, 106 Zhongshan Second Road, Guangzhou, Guangdong 510080, P.R. China

E-mail:miyadu@hotmail.com

Dr Yangqiu Li, Institute of Hematology, Jinan University, 601 West Huangpu Avenue, Guangzhou, Guangdong 510632, P.R. China E-mail: yangqiuli@hotmail.com

*Contributed equally

Abbreviations: T-ALL, acute T-cell lymphoblastic leukemia; ATLL, adult T-cell leukemia/lymphoma; TCR, T-cell receptor; ND, newly diagnosed; MR, minor remission; $\mathrm{CR}$, complete remission; MRD, minimal residual disease; ATO, arsenic trioxide; VDLCP, vincristine, daunorubicin, L-asparaginase, cyclophosphamide and prednisone; HyperCVAD-A, cyclophosphamide, vincristine, doxorubicin and dexamethasone; HyperCVAD-B, mitoxantrone and cytarabine; CAT, cyclophosphamide, cytarabine and topotecan; CT, cyclophosphamide and topotecan; MP, methylprednisolone.

Key words: acute T-lymphocyte leukemia, T-cell receptor, T-cell clonality, arsenic trioxide, minimal residual disease treatment. This result is encouraging, and the present study has shown that malignant TCR $\alpha \beta^{+}$cell clones can be detected at the molecular level using reverse transcription-polymerase chain reaction (PCR) combined with the GeneScan technique. The result is mainly based on the T-cell receptor (TCR) V $\beta 1$ clone (a 190-base pair PCR product that with the same complementarity determining region 3 length can be detected for all samples collected during various statuses) and on undetectable TCR V $\gamma$ subfamily members, at the time of disease diagnosis. It is important to analyze the dynamically changing TCR pool in leukemia patients during therapy. Although the molecular mechanism through which arsenic contributes to malignant clone elimination remains unclear in the case presented, the use of arsenic is expected to be effective for clinically treating refractory and relapsed T-ALL patients.

\section{Introduction}

T-cell acute lymphoblastic leukemia (T-ALL) comprises aggressive hematological tumors that derive from the malignant transformation of T-cell progenitors. T-ALL accounts for $10-15 \%$ of pediatric and $25 \%$ of adult acute lymphoblastic leukemia (ALL) cases (1). With the introduction of improved treatment regimens, including risk-adapted chemotherapy, hematopoietic stem cell transplantation (HSCT) and supportive care, the prognosis of T-ALL has gradually improved and cure rates have reached over $85 \%$ in children and $\sim 50 \%$ in adults (2,3). However, the outcome of T-ALL patients with relapsed and refractory leukemia remains poor (1-3). Various novel therapeutic strategies have been recently studied, including tyrosine kinase inhibitors (TKIs) for the treatment of breakpoint cluster region-Abelson (BCR-ABL)-positive T-ALL and $\gamma$-secretase inhibitors (GSIs) for the treatment of T-ALLs with aberrant Notch 1 activation (4). Arsenic compounds have also been previously used to treat T-ALL cell lines and patients (5-8). Several studies have demonstrated that a safe and effective serum concentration of arsenic trioxide (ATO; 2-6 $\mu \mathrm{mol} / \mathrm{l}$ ) for treating acute promyelocytic leukemia (APL) patients could induce apoptosis in T-cell leukemia cell lines, notably in the Molt-4 cell line, or in leukemia cells from 
glucocorticoid-resistant ALL patients, independently or in combination with other agents, such as glucocorticoids (6-9). The combination of ATO and other common chemotherapy drugs provides a therapeutic target that may potentially be used to induce the remission of relapsed or refractory T-ALL patients.

During normal T-cell development, the earliest established T-cell lineage, immature cluster of differentiation (CD) $34^{+}$ cells, enter the thymus and subsequently differentiate into mature T-cells, gaining a functional T-cell receptor (TCR) that belongs to the $\alpha \beta$ or $\gamma \delta$ lineage (10). T-cells implicated in T-ALL are characterized by the clonal expansion of malignant T-cells arrested at an early stage during T-cell differentiation (1). Clonally expanded malignant T-cells (leukemic clones) vary in certain patients due to TCR gene rearrangement diversity $(11,12)$. The combination of reverse transcription (RT)-polymerase chain reaction (PCR) and the GeneScan technique, also referred to as 'immunoscope', has been widely used to analyze TCR repertoires and dynamically monitor clonal changes in T-cells in patients with leukemia and other diseases, including autoimmune diseases and certain types of viral infections $(13,14)$. Using this method, the immune status of patients could be characterized and the evolution of malignant T-cell clones identified, which may aid in monitoring minimal residual disease (MRD) and designing specific therapeutic strategies for T-ALL $(12,15)$. The present study reports a rare case of T-ALL, whereby the patient responded poorly to standard chemotherapy but achieved complete remission (CR) following treatment with protocols involving arsenic. In order to evaluate the effects of the treatment and monitor the reconstitution of the immune system following treatment with arsenic-combined regimens, the TCR $\beta, \gamma$ and $\delta$ repertoires of the T-ALL patient were monitored at 7 time points, between the time of diagnosis and when CR was achieved, over 4 months.

\section{Case report}

A 28-year-old male patient presented to Department of Hematology, Guangdong General Hospital (Guangzhou, China) due to dizziness in January 2013. The physical examination disclosed lymphadenopathy, splenomegaly and hepatomegaly, and no skin lesions were present. A complete blood count revealed a white blood cell count of $12 \times 10^{10} / 1$ (normal range, $\left.4-10 \times 10^{9} / 1\right)$. Cytogenetic analysis showed a normal male karyotype 46XY with 5 aneuploids. In the peripheral blood (PB) and bone marrow (BM) aspirate smears, a high percentage of blasts (70 and 84\%, respectively) were detected (normal, $<0.01 \%$ in $\mathrm{PB}$ and $<2 \%$ in $\mathrm{BM}$ ). For immunophenotyping analysis and MRD monitoring, the following monoclonal antibodies were used: CD45-Percp, CD71-FITC, CD7-FITC, CD2-PE, CD5-APC, CD10-PE, CD34-FITC, CytoCD3-FITC, TdT-PE, CD33-PE, CD13-PE, CD56-PE, HLA-DR-PE, CD9-PE, CD4-FITC, CD8-PE (BD Biosciences, San Jose, CA, USA). The extracellular and intracellular staining were performed according to the manufacturer's instructions. A total of 30,000 cells were analyzed on a BD FACSCanto ${ }^{\mathrm{TM}}$ II flow cytometer (BD Biosciences) and data analysis was performed with CellQuest software (BD Biosciences). Flow cytometry (FCM) revealed that lymphoblasts accounted for $98.3 \%$ of the $30,000 \mathrm{BM}$ cells counted, the majority of which were positive for CD71, CD7, CD2, CD5, CD10, CD34, cytoCD3 and terminal deoxynucleotidyl transferase, and a number of which were positive for CD33, CD13, CD56, human leukocyte antigen-antigen D related, CD9, CD38 and sCD3, while CD4 and CD8 were not expressed (Fig. 1A; Table I). Fluorescence in situ hybridization (FISH) analysis showed no evidence for BCR-ABL, mixed-lineage leukemia gene (MLL) or fms related tyrosine kinase 3 (FLT3) gene rearrangements or deletions. Other laboratory tests included a basic metabolic panel, liver test and coagulopathy panel, and renal function, which were all unremarkable. The present case was diagnosed with T-ALL based on cytomorphology, immunohistochemistry and cytogenetic and molecular analysis.

The patient was admitted in January 2013 and started on one course of vineristine, $2 \mathrm{mg}$, once a day (days 1, 8, 15 and 22); daunorubicin, $68 \mathrm{mg}$, once a day (days 1, 2, 3, 15 and 16); cyclophosphamide, 1,200 $\mathrm{mg}$, once a day (days 1 and 15); L-asparaginase, 10,000 u (days 11, 14, 17, 20, 23 and 26); dexamethasone, $10 \mathrm{mg}$, once a day (days 1-14) and $5 \mathrm{mg}$, once a day (days 15-28) (VDLCP) regimen, followed by cyclophosphamide, $500 \mathrm{mg}$, every $12 \mathrm{~h}$ (days 1, 2 and 3); daunorubicin, $85 \mathrm{mg}$, once a day (day 4); vineristine, $2 \mathrm{mg}$, once a day (days 4 and 11); prednisone, $40 \mathrm{mg}$, once a day (days 1-4 and 11-14) (HyperCVAD-A) protocol, which is a more intensive chemotherapy regimen $(16,17)$. However, the patient had poor response to the initial chemotherapy consisting of one course of VDLCP and one course of HyperCAVD-A (Fig. 1B) $(13,14)$. One course of cyclophosphamide, cytarabine and topotecan (CAT) chemotherapy [cyclophosphamide, $400 \mathrm{mg}$, every $12 \mathrm{~h}$ (days 1-3); cytarabine, 1,500 mg, once a day (days 2-6); topotecan, $2 \mathrm{mg}$, once a day (days 2-6)] was then administered; however, the response assessments unfortunately indicated minor remission. Considering the refractory situation of the present patient, who failed to respond to the first and second line chemotherapeutics, ATO (which is widely used for treating APL and may be used as a saving treatment refractory leukemia cases) was then administered as salvage chemotherapy for the present patient. ATO $(10 \mathrm{mg}$; $0.16 \mathrm{mg} / \mathrm{kg} /$ day) was administered by intravenous drip for 2-3 h once a day, and treatment was continued for 3 weeks. On August 29, 2013, the patient surprisingly achieved CR with MRD, with $2.8 \%$ of blast T-cells identified in the BM by FCM (Fig. 1C; Table I). The patient was continued on cyclophosphamide, $400 \mathrm{mg}$, every $12 \mathrm{~h}$ (days 1 and 2); topotecan, $2 \mathrm{mg}$, every day (days 2-4), oral arsenic (10 mg, once a day), methylprednisolone (MP; $100 \mathrm{mg}$, at night), and mitoxantrone and cytarabine (HyperCVAD-B), alternated with consolidation therapy, which enabled the patient to maintain $\mathrm{CR}$ without MRD (Fig. 1D; Table I). Arsenic-related hematological toxicity or extra-hematological toxicities were not observed during the time of treatment. The treatment details and information regarding the seven bone marrow samples collected at various time points are summarized in Table I.

To monitor the T-cells in the BM of the present patient during the burden of disease and evaluate the effects of treatment, repertoire-specific PCR primers and the GeneScan technique were used in combination, as previously described (18-20). The TCR V $\beta$ (Fig. 2), V $\gamma$ and V $\delta$ (Fig. 3) repertoires were dynamically characterized in BM samples collected at various times (Table I). The result showed only a subset of the TCR V $\beta$ 
Table I. Sample and clinical therapy details for the present patient with refractory T-cell acute lymphoblastic leukemia.

\begin{tabular}{|c|c|c|c|c|c|c|}
\hline $\begin{array}{l}\text { Sample } \\
\text { collection }\end{array}$ & $\begin{array}{c}\text { Date of } \\
\text { collection }\end{array}$ & $\begin{array}{l}\text { Date of } \\
\text { therapy }\end{array}$ & $\begin{array}{l}\text { Type of } \\
\text { therapy }\end{array}$ & $\begin{array}{c}\text { Smear } \\
\text { analysis blast } \\
\text { cells in } \\
\text { BM/PB, \% }\end{array}$ & $\begin{array}{c}\text { FCM } \\
\text { analysis blast } \\
\text { cells in } \\
\text { BM, \% }\end{array}$ & $\begin{array}{c}\text { Disease } \\
\text { status at } \\
\text { sample } \\
\text { acquisition }\end{array}$ \\
\hline A & 31.01 .2013 & & & $84 / 70$ & 98.3 & ND \\
\hline B & 20.02 .2013 & $04.02-28.02 .2013$ & VDLCP & $79 / 66$ & 43.3 & MR \\
\hline $\mathrm{C}$ & 03.04 .2013 & $04.04-17.04 .2013$ & HyperCVAD-A & $62 / 5$ & 73.3 & MR \\
\hline $\mathrm{D}$ & 27.05 .2013 & $\begin{array}{l}29.05-22.06 .2013 \\
15.07-06.08 .2013\end{array}$ & $\begin{array}{l}\text { CAT } \\
\text { ATO }\end{array}$ & $92 / 40$ & & $\begin{array}{l}\text { MR } \\
\text { MR }\end{array}$ \\
\hline $\mathrm{E}$ & 29.08 .2013 & $29.08-26.10 .2013$ & ATO & $4 / 0$ & 2.8 & $\mathrm{CR}+\mathrm{MRD}$ \\
\hline $\mathrm{F}$ & 31.10 .2013 & $31.10-05.11 .2013$ & $\mathrm{ATO}+\mathrm{CT}$ & $2 / 0$ & 0.0 & CR \\
\hline G & 30.12 .2013 & $\begin{array}{c}03.01-24.01 .2014 \\
03.28-01.04 .2014 \\
16.07-18.07 .2014 \\
18.07 .2014-\text { present }\end{array}$ & $\begin{array}{l}\text { ATO+MP } \\
\text { ATO+CT } \\
\text { ATO+HyperCVAD-B } \\
\text { ATO }\end{array}$ & $\begin{array}{l}2 / 0 \\
2 / 0 \\
1 / 0\end{array}$ & $\begin{array}{l}0.0 \\
0.0 \\
0.0\end{array}$ & $\begin{array}{l}\mathrm{CR} \\
\mathrm{CR} \\
\mathrm{CR} \\
\mathrm{CR}\end{array}$ \\
\hline
\end{tabular}

FCM, flow cytometry; BM, bone marrow; PB, peripheral blood; VDLCP, vincristine, daunorubicin, L-asparaginase, cyclophosphamide and dexamethasone; HyperCVAD-A, cyclophosphamide, vincristine, doxorubicin and dexamethasone; CAT, cyclophosphamide, cytarabine and topotecan; ATO, arsenic trioxide; CT, cyclophosphamide and topotecan; MP, methylprednisolone; HyperCVAD-B, mitoxantrone and cytarabine; ND, newly diagnosed; MR, minor remission; CR, complete remission; MRD, minimal residual disease.
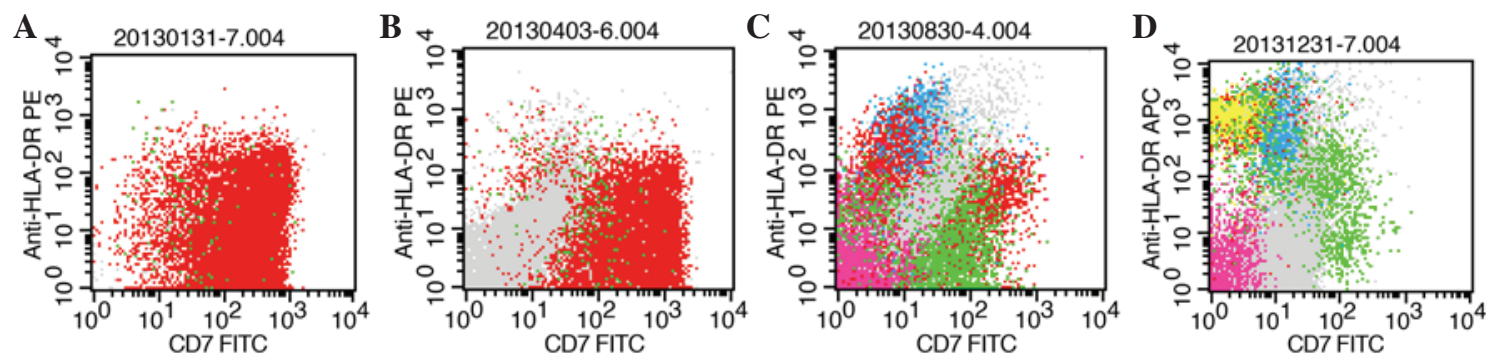

Figure 1. FCM for CD7 and HLA-DR expression analysis of the bone marrow at various disease states. Red scatter points represent the lymphoblast in bone marrow. Pink, green, blue, yellow and gray dots represent nucleated erythrocytes, mature lymphocytes, monocytes, pre-B lymphocytes and mature granulocytes, respectively, which gated in 2D spot figure (CD45-Percp and Side Scatter-Height). (A) Time of new diagnosis with T-cell acute lymphoblastic leukemia. FCM detected $98.3 \%$ blast cells, and the majority of the blast cells were positive for CD7 and HLA-DR. (B) Time of achieving minor remission following treatment with the vincristine, daunorubicin, L-asparaginase, cyclophosphamide and prednisone regimen and the cyclophosphamide, vincristine, doxorubicin and dexamethasone regimen. FCM detected $73.3 \%$ blast cells. (C) Time of achieving CR following treatment with ATO. FCM detected 2.8\% MRD and few cells were positive for CD7 and HLA-DR. (D) Time of CR that was maintained for 4 months in which no significant MRD could be detected by FCM. Scarce cells positive for CD7 and HLA-DR were found. FCM, flow cytometry; CD7, cluster of differentiation 7; HLA-DR, human leukocyte antigen-antigen D related; CR, complete remission; MRD, minimal residual disease; FITC, fluorescein isothiocyanate.

family members (9-16) were detectable in each of the samples collected at various time points (Fig. 2), which is in contrast with healthy individuals, who express nearly all of the TCR V $\beta$ repertoire subfamily members $(18,21)$. Although the expression of all of the TCR $V \gamma$ and $V \delta$ family members was not found in each sample (Fig. 3), the expression pattern did not appear to be significantly different compared with the healthy individuals from a previous study (19), particularly when the patient achieved CR. Significantly, oligoclonally expanded T-cells were detected in certain TCR V $\beta$ (V $\beta 1, V \beta 21$ and

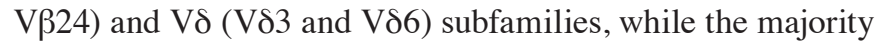
of TCR subfamily T-cells displayed a polyclonal pattern. The evolution of T-cell clones was characterized at various time points prior to and following chemotherapy, particularly for the oligoclonally-expanded TCR subset, to detect a factor associated with outcome and to identify a malignant T-ALL clone.
Oligoclonally-expanded TCR V $\beta 1$ T-cells of the same size [same complementarity determining region 3 (CDR3) length; PCR products, 190 base pairs (bp)] were identified at the time the patient was diagnosed with T-ALL (Fig. 4A), during VDLCP (Fig. 4B), and following HyperCAVD-A (Fig. 4D), displaying an oligoclonal trend at the chemotherapy-free interval between VDLCP and HyperCAVD therapy (Fig. 4C). After ATO therapy, prior to achieving CR, FCM demonstrated $2.82 \%$ blast $\mathrm{T}$-cells in the BM, and the V $\beta 1$ subfamily profile displayed an oligoclonal trend with three peaks of products of various sizes, while the 190-bp T-cell clone product remained visible (Fig. 4E). Moreover, the V $\beta 1$ cell clone product of 190 bp appeared at the time when the T-ALL case remained in CR without MRD. The V $\beta 1$ clone profile distinctly showed that the major V $\beta 1$ clone in the sample at 2 months following $\mathrm{CR}$ was different compared with samples prior to $\mathrm{CR}$; the 


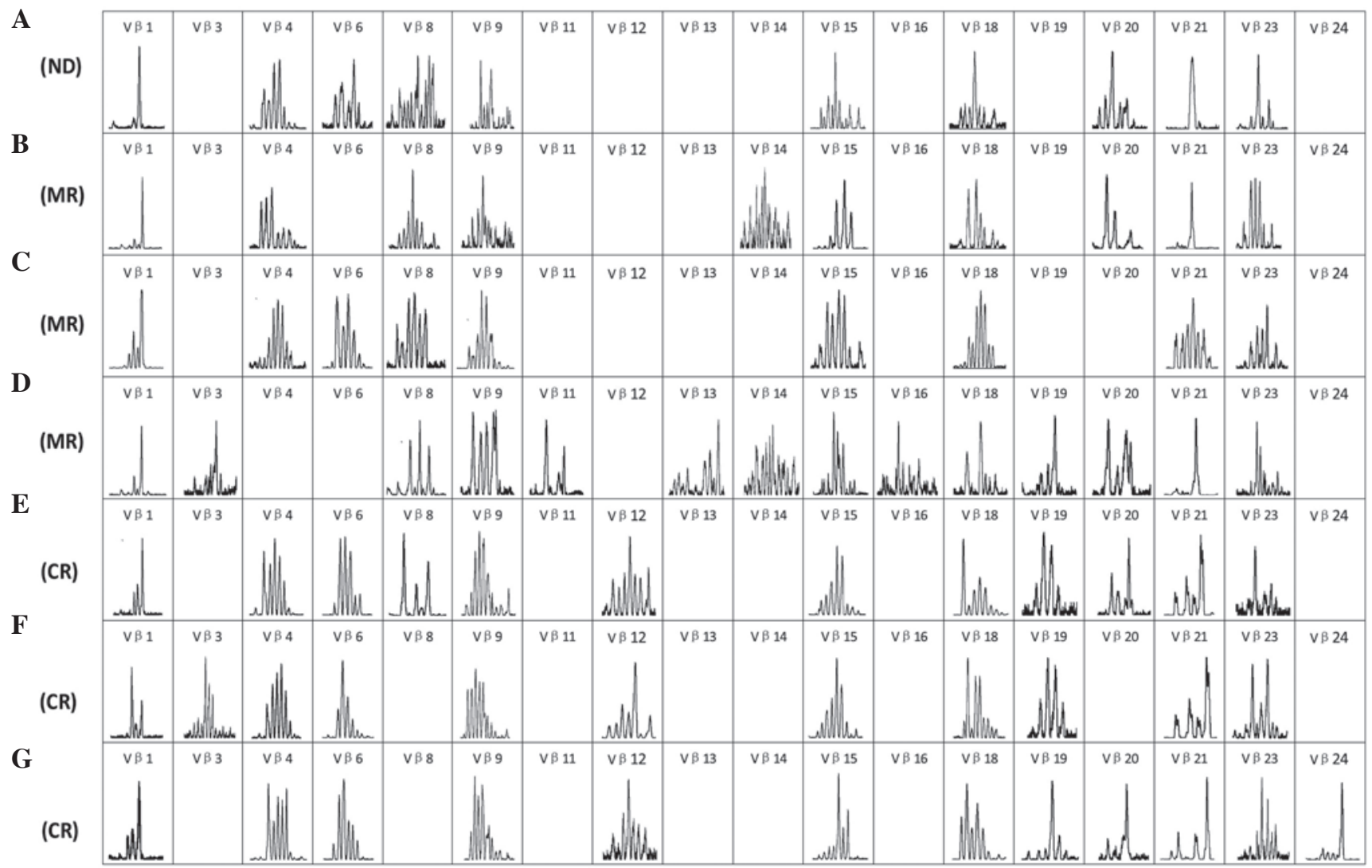

Figure 2. Complementarity determining region 3 spectratyping of the T-cell receptor V $\beta$ subfamily on T-cells in the bone marrow at 7 time points. (A) Time of diagnosis with T-cell acute lymphoblastic leukemia. (B) Time of achieving MR following treatment with vincristine, daunorubicin, L-asparaginase, cyclophosphamide and prednisone regimen. (C) Time of achieving MR prior to treatment with the HyperCVAD-A regimen. (D) Time of achieving MR following treatment with the HyperCVAD-A regimen. (E) Time of achieving CR but with MRD following treatment with cyclophosphamide, cytarabine and topotecan and ATO. (F) Time of achieving CR with no MRD detected following treatment with a second course of ATO. (G) Time of CR that was maintained for 4 months in which no significant MRD could be detected by flow cytometry. ND, newly diagnosed; MR, minor remission; CR, complete remission; MRD, minimal residual disease; HyperCVAD-A, cyclophosphamide, vincristine, doxorubicin and dexamethasone; ATO, ATO, arsenic trioxide.

clone product was $184 \mathrm{bp}$ in size, while the $190 \mathrm{bp}$ product remained present as a minor clone (Fig. 4F). Notably, the V $\beta 1$ cell clone product of $190 \mathrm{bp}$ became the major clone again 4 months subsequent to CR (Fig. 4G). At the time, MRD was not detected by FCM; however, the relative fluorescence intensity of V $\beta 1$ was remarkably decreased compared with samples collected in the stage without CR (data not shown). In addition to the $\mathrm{V} \beta 1$ subfamily, oligoclonality or an oligoclonal trend could also be detected for the V $\beta 21$ or V $\beta 24$ subfamily, which had various product sizes or clones for certain patient samples. Overall, based on the evolution of the V $\beta 1 \mathrm{~T}$-cell clones, the V $\beta 1$ T-cell clone appearing with the 190-bp product may be the malignant T-ALL clone, as the numbers of this clone decreased following chemotherapy, particularly ATO therapy.

Malignant T-ALL clones may express alternative TCR $\alpha \beta$ or $\gamma \delta$ receptors (8); therefore, the TCR $\mathrm{V} \gamma$ and $\mathrm{V} \delta$ repertoires were also analyzed in all samples of the present case. Since skewed $\mathrm{V} \gamma$ and $\mathrm{V} \delta$ subfamily distribution is a common characteristic of the leukemia patients (19), similar results were expected and detected in the present study. In the present case, clonally expanded V83 T-cell clones of the same size as CDR3 were identified in all samples at various time points (Fig. 3); however, no $\mathrm{V} \gamma$ subfamily members were detected in 3 of the samples (Fig. 3). This inconsistency may be due to a relatively low frequency of $\gamma \delta^{+} \mathrm{T}$-cells in the samples, which were not detected using the present techniques. Furthermore, it appears unlikely that the V83 T-cell clone is the malignant T-ALL clone in this case, as $\mathrm{V} \gamma$ subfamily members that should pair with $\mathrm{V} \delta$ to form $\gamma \delta^{+}$T-cell clones could not be detected at the time of diagnosis (Fig. 3A), which also supports the theory that malignant T-ALL clones should be $\alpha \beta^{+}$T-cell clones expressing V $\beta 1$.

Written informed consent was obtained from the patient for publication of the present study and any accompanying images.

\section{Discussion}

The present study may be the first documented case of a patient with T-ALL that achieved CR by ATO induction treatment, although the achieved CR may not hold true on a molecular level (indicated by the results of the T-cell repertoire analysis). Medicinal uses of arsenic have been documented for $>2,000$ years. ATO has been previously shown to be dramatically effective for treating patients with APL $(22,23)$, and is also effective in $20 \%$ of patients with myelodysplastic syndrome (MDS) $(24,25)$. The mechanisms of ATO-induced apoptosis include the degradation of promyelocytic leukemia (PML)-retinoic acid receptor $\alpha$ (RAR $\alpha$ ), which may occur with or without the interference of B cell lymphoma-2 (Bcl-2) family genes $(8,26,27)$. Several other mechanisms of ATO anti-leukemic effects have been identified, including the 


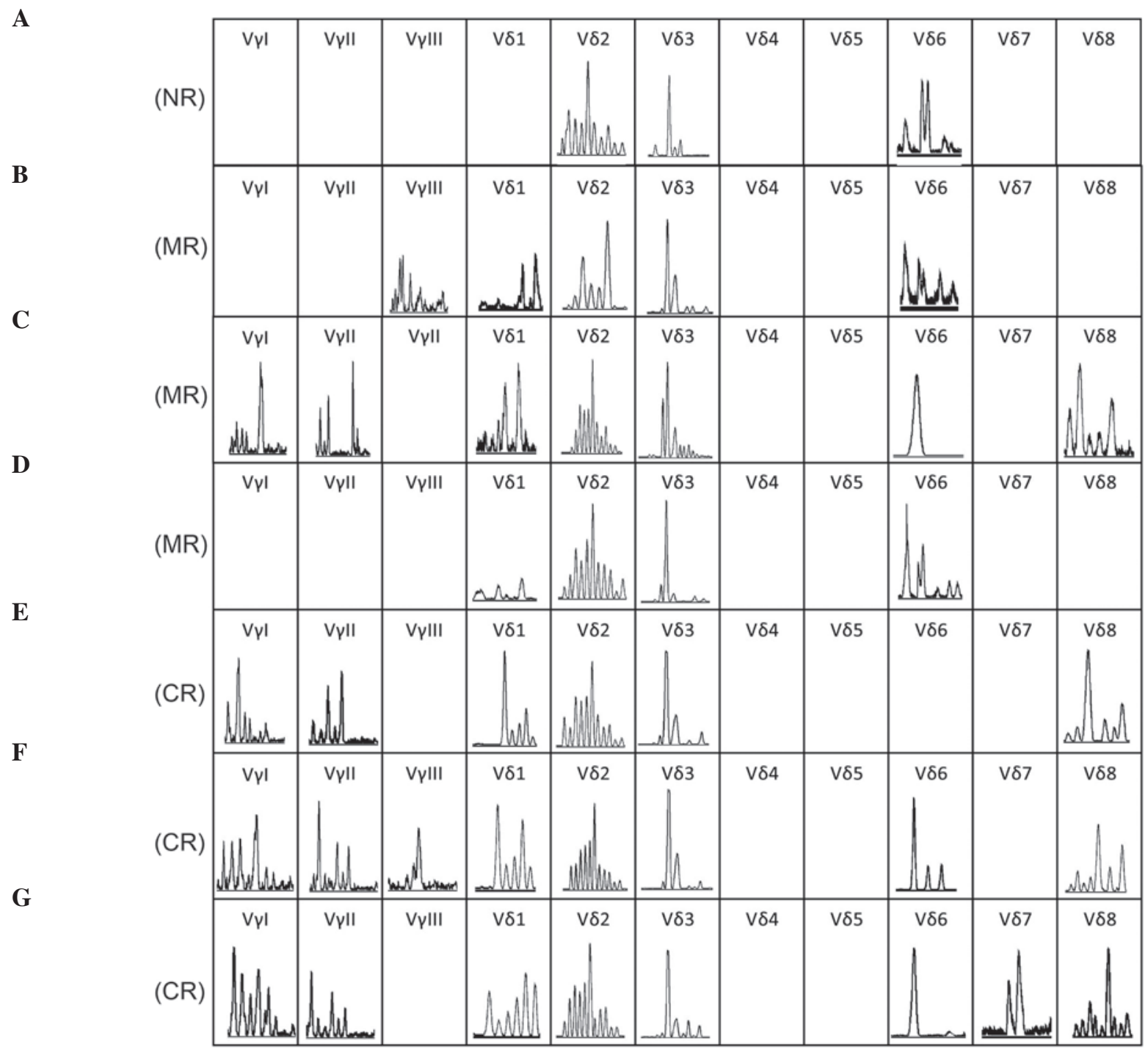

Figure 3. Complementarity determining region 3 spectratyping of the T-cell receptor V $\gamma$ and V $\delta$ subfamilies on T-cells in the bone marrow at 7 time points. (A) Time of new diagnosis with T-cell acute lymphoblastic leukemia. (B) Time of achieving MR following treatment with vincristine, daunorubicin, L-asparaginase, cyclophosphamide and prednisone. (C) Time of achieving MR prior to treatment with the HyperCVAD-A regimen. (D) Time of achieving MR upon treatment with the HyperCVAD-A regimen. (E) Time of achieving CR, but with MRD subsequent to treatment with cyclophosphamide, cytarabine and topotecan and ATO. (F) Time of achieving CR without MRD detected following treatment with a second course of ATO. (G) Time of CR that was maintained for 4 months in which no significant MRD could be detected by flow cytometry. ND, newly diagnosed; CR, complete remission; MR, minor remission; MRD, minimal residual disease; HyperCVAD-A, cyclophosphamide, vincristine, doxorubicin and dexamethasone; ATO, arsenic trioxide.

induction of PML-RAR $\alpha$-independent apoptosis, cell cycle arrest, growth inhibition, induction of stress related processes, direct mitochondrial damage and the inhibition of nuclear factor- $\kappa \mathrm{B}(\mathrm{NF}-\kappa \mathrm{B})(8,26-31)$. Based on the dramatic effects of ATO on APL and the partial effects on MDS, several studies have tested the efficacy of ATO on other malignant T-cell lines. ATO has been demonstrated to selectively inhibit growth and induce apoptosis in several cell lines, including the megakaryocytic leukemia cell lines HEL, Meg-01, UT7, and M07e (32), the myeloid leukemia cell lines U937 and KG-1, plasma cells and cell lines from myeloma patients (33) and B cell leukemia cell lines (34). Notably, ATO has been demonstrated to be capable of inducing apoptosis in certain solid tumor cells, for example non-small cell lung cancer cells and sarcoma cells $(35,36)$, demonstrating the broad antitumor activity of arsenic. Due to a lack of effective treatments against adult T-cell leukemia/lymphoma (ATLL), ATO activity was also tested in vitro in several HTLV-1-infected cell lines. In 1998, a Japanese group conducted the first in vitro studies on the comparative effects of ATO and retinoic acid (RA) on HTLV-1-infected cell lines and fresh ATL cells (37). Subsequently, several in vitro studies indicated that ATO combined with interferon- $\alpha$ (IFN- $\alpha$ ) is a promising therapy for ATLL (38-41). The surprising specificity of the cellular effects of ATO, by exclusively targeting the viral oncoprotein $\mathrm{p} 40$, human T-lymphotropic virus (Tax) and the NF- $\kappa \mathrm{B}$ pathway, provided a biological basis for dual IFN- $\alpha / \mathrm{As}_{2} \mathrm{O}_{3}$ treatment for ATLL patients (42). At present, several studies have reported phase II trial results of dual IFN- $\alpha / \mathrm{As}_{2} \mathrm{O}_{3}$ treatment in relapsed/refractory ATLL $(23,43,44)$. The majority of these studies exhibited feasible anti-leukemia effects in ATL patients with a poor prognosis, even though the treatment context should be optimized $(23,43,44)$. In addition, arsenic, IFN- $\gamma$ and zidovudine were shown to be important 


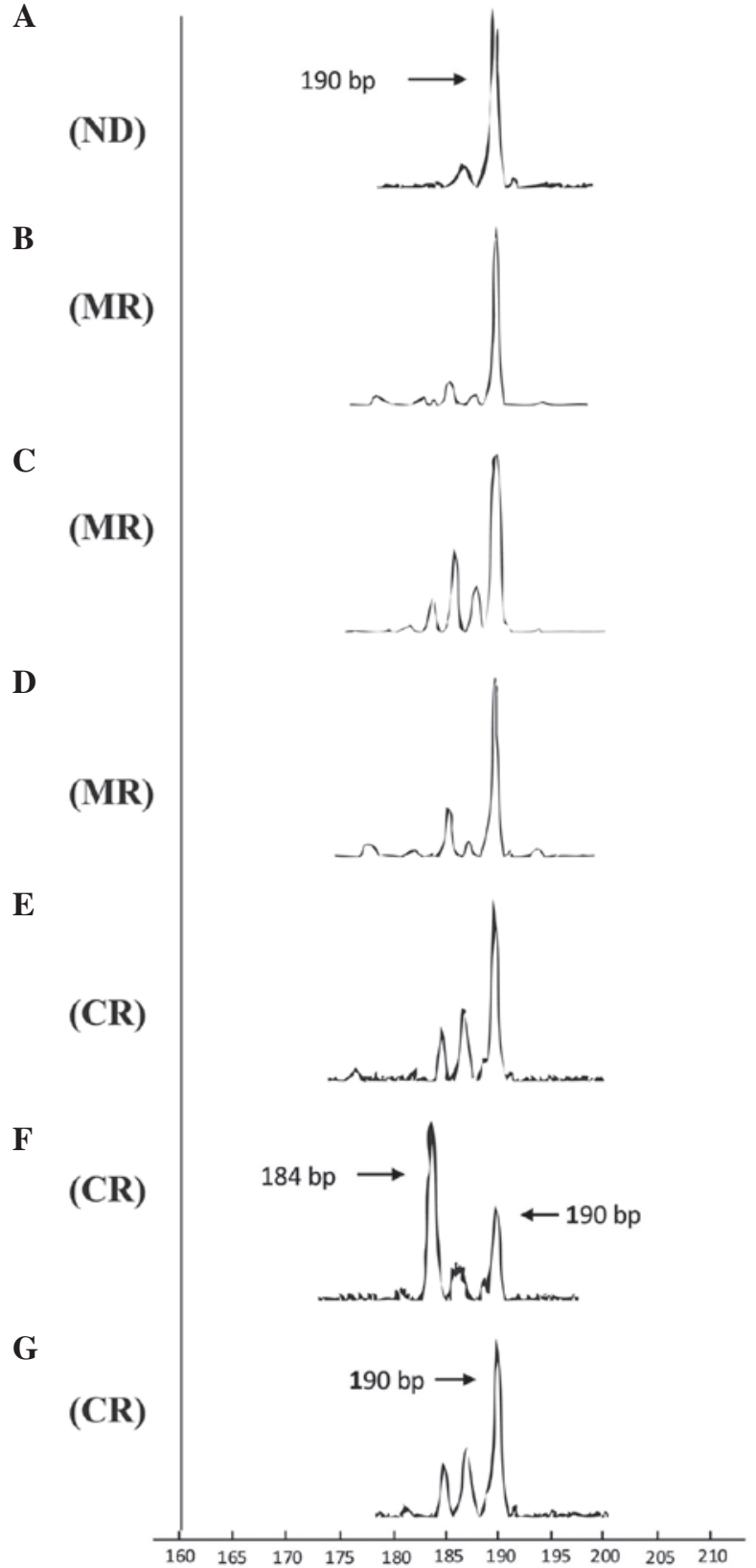

Figure 4. Dynamic changes in complementarity determining region 3 spectratyping of V $\beta 1 \mathrm{~T}$-cells in samples at various time points. The horizontal axis represent the product size and the height of a single peak in each graph represents the fluorescence intensity of product in corresponding size. (A) Time of new diagnosis with T-cell acute lymphoblastic leukemia. (B) Time of achieving MR following treatment with the vincristine, daunorubicin, L-asparaginase, cyclophosphamide and prednisone regimen. (C) Time of achieving MR prior to treatment with the HyperCVAD-A regimen. (D) Time of achieving MR following treating with the HyperCVAD-A regimen. (E) Time of achieving CR but with MRD upon treatment with cyclophosphamide, cytarabine and topotecan and ATO. (F) Time of achieving CR with no MRD detected following treating with a second course of ATO. (G) Time of CR that was maintained for 4 months in which no significant MRD could be detected by flow cytometry. ND, newly diagnosed; MD, minor remission; $\mathrm{CR}$, complete remission; MRD, minimal residual disease; HyperCVAD-A, cyclophosphamide, vincristine, doxorubicin and dexamethasone; ATO, ATO, arsenic trioxide.

for restoring immunocompetent microenvironments, thus enhancing the eradication of ATL cells (45). This mechanism may be secondary to arsenic or IFN- $\gamma$-induced Tax degradation and the reversal of NF-KB activation (45).
With the promising role of arsenic and arsenic combined with dual or triple treatment in ATLL, and the specific effects of arsenic compounds in the treatment of APL, one study investigated the potential of using arsenic to treat relapsed or refractory ALL (5). The disappointing result showed that ATO was not active in the treatment of ALL in a cohort of 11 patients [5 early pre-acute B-cell lymphoblastic leukemia (B-ALL), 2 pre-B-ALL, 1 mature B-ALL and 3 T-ALL] in 2006 (5). However, this result should not preclude additional evaluation of arsenic in combination therapies for ALL. For example, a previous study reported that subtoxic doses of ATO and glucocorticoids could be advantageous for the treatment of glucocorticoid-resistant ALL cells from T- and precursor B-ALL patients (6). The underlying pro-apoptosis mechanism partially depended on the inhibition of the protein kinase $\mathrm{B} / \mathrm{X}$-linked inhibitor of apoptosis protein pathway and the activation of the pro-apoptosis Bcl-2 family member, Bcl-2 associated agonist of cell death (6). In addition, the cytotoxicity effect with an $80 \%$ inhibition rate of ATO in the Molt- 4 cell line was reported to involve apoptosis and autophagy via the upregulation of Beclin-1 at the post-transcriptional level $(8,9)$. The pre-clinical evidence indicated that ATO alone or combined with other chemotherapy regimens have a potential capability in treating T-ALL patients via complicated mechanisms $(6,8,9)$. In the present study, the T-ALL patient had a poor response to induction remission regimens, so the patient was treated with a protocol involving arsenic, which is a salvaging treatment for refractory leukemia patients in the Department of Hematology, Guangdong General Hospital. Notably, the patient responded well to arsenic treatment regimens without evident toxicity. At present, it is unknown whether the successful treatment of the present case was due to the therapeutic strategy (drug-dose, route of administration or drug-combination) or to factors that rendered the patient sensitive to arsenic treatment. However, the present rare case at least provides support for the use of arsenic agents combined with other drugs, such as glucocorticoids, to treat T-ALL, as alternative salvage chemotherapy in the future.

In the present case, the restricted expression of the TCR $\mathrm{V} \beta, \mathrm{V} \gamma$ and $\mathrm{V} \delta$ repertoire subsets displayed a common characteristic of samples collected at various time points and various disease states. For example, restricted use of the TCR V $\beta$ subfamilies lacking V $\beta 2,5,7,10,17$ and 22 was shown (Fig. 4B). Previous studies have shown that TCR repertoire deficiency is a common characteristic of patients with leukemia, including those with T-ALL $(12,46)$. Potential reasons for deficiencies in the TCR repertoire include: i) The prior proliferation of a malignant T-cell clones suppressed the proliferation of normal T-cell clones, and ii) the tumor microenvironment or other unknown factors affect the competency of the immune system $(47,48)$. However, the T-cell repertoire deficiency was not significantly reconstituted even when the patient achieved $\mathrm{CR}$, as the reconstitution of the TCR repertoire is slow due to the cytotoxicity of chemotherapy (49). In addition, little is known of the mechanisms by which arsenic therapy inhibits T-cell proliferation (6). However, the continued presence of certain TCR subfamilies, including V $\beta 12$ and V $\beta 19$, at various time points of CR may indicate the reconstitution of the TCR repertoire to a certain extent. 
Unlike T-ALL patients following HSCT, in which T-ALL clones are eradicated and not detected at the molecular level by GeneScan analysis, V $\beta 1$ T-cell clones of the same size could be detected at all time points in the present case, even when the patient achieved CR lasts for $>4$ months. This result suggests that molecular CR cannot be achieved in cases treated with arsenic and chemotherapy. The result also has significant implications for MRD monitoring using specific clonal T-cell detection by GeneScan and RT-PCR, which may provide dynamic information for disease states and direct further therapy (12).

In the majority of cases with cancer or leukemia, an antitumor T-cell clone could be identified in patient samples (blood, BM or tumor tissue) even if the patient had immunodeficiency $(46,50)$, In the present study, clonally expanded $\mathrm{V} \beta 21, \mathrm{~V} \beta 24, \mathrm{~V} \delta 3$ and $\mathrm{V} \delta 6$ were identified in certain samples collected from various time points, and whether such clonally expanded T-cells are special responders to T-ALL therapy requires further investigation.

In conclusion, the present reported that arsenic induced CR in a case with refractory T-ALL, which supports an alternative salvage therapeutic method for clinically treating refractory and relapsed T-ALL patients. However, the prolonged response to arsenic associated with treatment and the associated toxicity requires additional studies. The distribution and clonality of the TCR $\beta, \gamma$ and $\delta$ repertoires were characterized in samples from various time points from the patient. The results suggested that the evolution of a malignant T-ALL clone occurred, indicating that arsenic therapy may be unable to induce molecular CR in T-ALL patients. Therefore, dynamically monitoring the TCR repertoire distribution and clonal evolution combined with clinical course analysis would aid in predicting the prognosis of the patient and in designing specific therapeutic strategies.

\section{Acknowledgements}

The present study was supported by the National Natural Science Foundation of China (grant nos. 91129720 and 81100384), the Collaborated Grant for HK-Macao-TW of the Ministry of Science and Technology (grant no. 2012DFH30060) and the Guangdong Science \& Technology Project (Guangdong, China; grant no. 2012B050600023).

\section{References}

1. Van Vlierberghe P and Ferrando A: The molecular basis of T cell acute lymphoblastic leukemia. J Clin Invest 122: 3398-3406, 2012.

2. Bhojwani D and Pui CH: Relapsed childhood acute lymphoblastic leukaemia. Lancet Oncol 14: e205-e217, 2013.

3. Van der Meulen J, Van Roy N, Van Vlierberghe P and Speleman F: The epigenetic landscape of T-cell acute lymphoblastic leukemia. Int J Biochem Cell Biol 53: 547-557, 2014.

4. Koyama D, Kikuchi J, Hiraoka N, Wada T, Kurosawa H, Chiba S and Furukawa Y: Proteasome inhibitors exert cytotoxicity and increase chemosensitivity via transcriptional repression of Notch1 in T-cell acute lymphoblastic leukemia. Leukemia 28: 1216-1226, 2014.

5. Litzow MR, Lee S, Bennett JM, Dewald GW, Gallagher RE, Jain V, Paietta EM, Racevskis J, Rousey SR, Mazza JJ and Tallman MS: A phase II trial of arsenic trioxide for relapsed and refractory acute lymphoblastic leukemia. Haematologica 91: 1105-1108, 2006.
6. Bornhauser BC, Bonapace L, Lindholm D, Martinez R, Cario G, Schrappe M, Niggli FK, Schäfer BW and Bourquin JP: Low-dose arsenic trioxide sensitizes glucocorticoid-resistant acute lymphoblastic leukemia cells to dexamethasone via an Akt-dependent pathway. Blood 110: 2084-2091, 2007.

7. Qian W, Liu J, Jin J, Ni W and Xu W: Arsenic trioxide induces not only apoptosis but also autophagic cell death in leukemia cell lines via up-regulation of Beclin-1. Leuk Res 31: 329-339, 2007.

8. $\mathrm{Hu} \mathrm{XM}$, Hirano T and Oka K: Arsenic trioxide induces apoptosis in cells of MOLT-4 and its daunorubicin-resistant cell line via depletion of intracellular glutathione, disruption of mitochondrial membrane potential and activation of caspase-3. Cancer Chemother Pharmacol 52: 47-58, 2003.

9. Jiao Y, Zhang W, Liu J, Ni W, Xu W, Jin J and Qian W: Telomere attrition and chromosome instability via downregulation of TRF2 contributes to arsenic trioxide-induced apoptosis of human T-Cell leukemia cell line molt-4 cells. Cancer Biol Ther 6: 1186-1192, 2007.

10. Taghon T, Waegemans E and Van de Walle I: Notch signaling during human $\mathrm{T}$ cell development. Curr Top Microbiol Immunol 360: 75-97, 2012.

11. Zheng H, Wang X, Ma Y, Xu B, Chen S, Yang L, Wu X, Przybylski GK, Huang S, Ye T and Li Y: The TCR $\gamma \delta$ repertoire and relative gene expression characteristics of T-ALL cases with

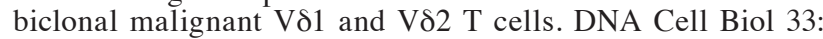
49-56, 2014.

12. Chen S, Huang X, Zheng H, Geng S, Wu X, Yang L, Weng J, Du X and Li Y: The evolution of malignant and reactive $\gamma \delta+\mathrm{T}$ cell clones in a relapse T-ALL case after allogeneic stem cell transplantation. Mol Cancer 12: 73, 2013.

13. Langerak AW, van Den Beemd R, Wolvers-Tettero IL, Boor PP, van Lochem EG, Hooijkaas H and van Dongen JJ: Molecular and flow cytometric analysis of the Vbeta repertoire for clonality assessment in mature TCRalphabeta T-cell proliferations. Blood 98: 165-173, 2001.

14. Prinz I, Thamm K, Port M, Weissinger EM, Stadler M, Gabaev I, Jacobs R, Ganser A and Koenecke C: Donor V $\delta 1+\gamma \delta \mathrm{T}$ cells expand after allogeneic hematopoietic stem cell transplantation and show reactivity against $\mathrm{CMV}$-infected cells but not against progressing B-CLL. Exp Hematol Oncol 2: 14, 2013.

15. Langerak AW, Szczepański T, van der Burg M, Wolvers-Tettero IL and van Dongen JJ: Heteroduplex PCR analysis of rearranged $\mathrm{T}$ cell receptor genes for clonality assessment in suspect $\mathrm{T}$ cell proliferations. Leukemia 11: 2192-2199, 1997.

16. Takeuchi J, Kyo T, Naito K, Sao H, Takahashi M, Miyawaki S, Kuriyama K, Ohtake S, Yagasaki F, Murakami H, et al: Induction therapy by frequent administration of doxorubicin with four other drugs, followed by intensive consolidation and maintenance therapy for adult acute lymphoblastic leukemia: The JALSG-ALL93 study. Leukemia 16: 1259-1266, 2002.

17. Kantarjian H, Thomas D, O'Brien S, Cortes J, Giles F, Jeha S, Bueso-Ramos CE, Pierce S, Shan J, Koller C, et al: Long-term follow-up results of hyperfractionated cyclophosphamide, vincristine, doxorubicin and dexamethasone (Hyper-CVAD), a dose-intensive regimen, in adult acute lymphocytic leukemia. Cancer 101: 2788-2801, 2004.

18. Li Y, Chen S, Yang L, Yin Q, Geng S, Wu X, Schmidt CA and Przybylski GK: TRAV and TRBV repertoire, clonality and the proliferative history of umbilical cord blood T-cells. Transpl Immunol 18: 151-158, 2007.

19. Li Y, Chen S, Yang L, Li B, Chan JY and Cai D: TRGV and TRDV repertoire distribution and clonality of T cells from umbilical cord blood. Transpl Immunol 20: 155-162, 2009.

20. Assaf C, Hummel M, Dippel E, Goerdt S, Müller HH, Anagnostopoulos I, Orfanos CE and Stein H: High detection rate of T-cell receptor beta chain rearrangements in T-cell lymphoproliferations by family specific polymerase chain reaction in combination with the GeneScan technique and DNA sequencing. Blood 96: 640-646, 2000.

21. Gorski J, Yassai M, Zhu X, Kissela B, Kissella B [corrected to Kissela B], Keever C and Flomenberg N: Circulating T cell repertoire complexity in normal individuals and bone marrow recipients analyzed by CDR3 size spectratyping. Correlation with immune status. J Immunol 152: 5109-5119, 1994.

22. Soignet SL, Frankel SR, Douer D, Tallman MS, Kantarjian H, Calleja E, Stone RM, Kalaycio M, Scheinberg DA, Steinherz P, et al: United States multicenter study of arsenic trioxide in relapsed acute promyelocytic leukemia. J Clin Oncol 19: 3852-3860, 2001 . 
23. Mahieux R and Hermine O: In vivo and in vitro treatment of HTLV-1 and HTLV-2 infected cells with arsenic trioxide and interferon-alpha. Leuk Lymphoma 46: 347-355, 2005.

24. Schiller GJ, Slack J, Hainsworth JD, Mason J, Saleh M, Rizzieri D, Douer D and List AF: Phase II multicenter study of arsenic trioxide in patients with myelodysplastic syndromes. J Clin Oncol 24: 2456-2464, 2006

25. Vey N, Bosly A, Guerci A, Feremans W, Dombret H, Dreyfus F, Bowen D, Burnett A, Dennis M, Ribrag V, et al: Arsenic trioxide in patients with myelodysplastic syndromes: A phase II multicenter study. J Clin Oncol 24: 2465-2471, 2006.

26. Chen GQ, Zhu J, Shi XG, Ni JH, Zhong HJ, Si GY, Jin XL, Tang W, Li XS, Xong SM, et al: In vitro studies on cellular and molecular mechanisms of arsenic trioxide (As2O3) in the treatment of acute promyelocytic leukemia: As2O3 induces NB4 cell apoptosis with downregulation of Bcl-2 expression and modulation of PML-RAR alpha/PML proteins. Blood 88: 1052-1061, 1996.

27. Galimberti S, Guerrini F, Salvi F, Petrini I, Gioia D, Messa E, Palumbo GA, Cilloni D, Petrini M and Levis A: Arsenic trioxide and ascorbic acid interfere with the BCL2 family genes in patients with myelodysplastic syndromes: An ex-vivo study. J Hematol Oncol 5: 53, 2012.

28. Yedjou $\mathrm{C}$, Tchounwou P, Jenkins $\mathrm{J}$ and McMurray R: Basic mechanisms of arsenic trioxide (ATO)-induced apoptosis in human leukemia (HL-60) cells. J Hematol Oncol 3: 28, 2010

29. Rojewski MT, Körper S and Schrezenmeier H: Arsenic trioxide therapy in acute promyelocytic leukemia and beyond: From bench to bedside. Leuk Lymphoma 45: 2387-2401, 2004.

30. Mathas S,Lietz A, Janz M, Hinz M,Jundt F, Scheidereit C, Bommert K and Dorken B: Inhibition of NF-kappaB essentially contributes to arsenic-induced apoptosis. Blood 102: 1028-1034, 2003.

31. Kumar S, Yedjou CG and Tchounwou PB: Arsenic trioxide induces oxidative stress, DNA damage and mitochondrial pathway of apoptosis in human leukemia (HL-60) cells. J Exp Clin Cancer Res 33: 42, 2014.

32. Lu M, Levin J, Sulpice E, Sequeira-Le Grand A, Alemany M, Caen JP and Han ZC: Effect of arsenic trioxide on viability, proliferation, and apoptosis in human megakaryocytic leukemia cell lines. Exp Hematol 27: 845-852, 1999.

33. Rousselot P, Labaume S, Marolleau JP, Larghero J, Noguera MH, Brouet JC and Fermand JP: Arsenic trioxide and melarsoprol induce apoptosis in plasma cell lines and in plasma cells from myeloma patients. Cancer Res 59: 1041-1048, 1999.

34. Akao Y, Mizoguchi H, Kojima S, Naoe T, Ohishi N and Yagi K: Arsenic induces apoptosis in B-cell leukaemic cell lines in vitro: Activation of caspases and down-regulation of $\mathrm{Bcl}-2$ protein. $\mathrm{Br}$ J Haematol 102: 1055-1060, 1998.

35. Li H, Zhu X, Zhang Y, Xiang J and Chen H: Arsenic trioxide exerts synergistic effects with cisplatin on non-small cell lung cancer cells via apoptosis induction. J Exp Clin Cancer Res 28: 110, 2009.

36. Chiu HW, Tseng YC, Hsu YH, Lin YF, Foo NP, Guo HR and Wang YJ: Arsenic trioxide induces programmed cell death through stimulation of ER stress and inhibition of the ubiquitin-proteasome system in human sarcoma cells. Cancer Lett 356: 762-772, 2015.

37. Ishitsuka K, Hanada S, Suzuki S, Utsunomiya A, Chyuman Y, Takeuchi S, Takeshita T, Shimotakahara S, Uozumi K, Makino T and Arima T: Arsenic trioxide inhibits growth of human T-cell leukaemia virus type I infected T-cell lines more effectively than retinoic acids. Br J Haematol 103: 721-728, 1998.
38. Bazarbachi A, El-Sabban ME, Nasr R, Quignon F, Awaraji C, Kersual J, Dianoux L, Zermati Y, Haidar JH, Hermine O and de Thé $\mathrm{H}$ : Arsenic trioxide and interferon-alpha synergize to induce cell cycle arrest and apoptosis in human T-cell lymphotropic virus type I-transformed cells. Blood 93: 278-283, 1999.

39. El-Sabban ME, Nasr R, Dbaibo G, Hermine O, Abboushi N, Quignon F, Ameisen JC, Bex F, de Thé H and Bazarbachi A: Arsenic-interferon-alpha-triggered apoptosis in HTLV-I transformed cells is associated with tax down-regulation and reversal of NF-kappa B activation. Blood 96: 2849-2855, 2000.

40. Ishitsuka K, Hanada S, Uozumi K, Utsunomiya A and Arima T: Arsenic trioxide and the growth of human T-cell leukemia virus type I infected T-cell lines. Leuk Lymphoma 37: 649-655, 2000.

41. Mahieux R, Pise-Masison C, Gessain A, Brady JN, Olivier R, Perret E, Misteli $\mathrm{T}$ and Nicot C: Arsenic trioxide induces apoptosis in human T-cell leukemia virus type 1- and type 2-infected cells by a caspase-3-dependent mechanism involving Bcl-2 cleavage. Blood 98: 3762-3769, 2001.

42. Nasr R, Rosenwald A, El-Sabban ME, Arnulf B, Zalloua P, Lepelletier Y, Bex F, Hermine O, Staudt L, de Thé $\mathrm{H}$ and Bazarbachi A: Arsenic/interferon specifically reverses 2 distinct gene networks critical for the survival of HTLV-1-infected leukemic cells. Blood 101: 4576-4582, 2003.

43. Ishitsuka K, Suzumiya J, Aoki M, Ogata K, Hara S and Tamura K: Therapeutic potential of arsenic trioxide with or without interferon-alpha for relapsed/refractory adult T-cell leukemia/lymphoma. Haematologica 92: 719-720, 2007.

44. Hermine O, Dombret H, Poupon J, Arnulf B, Lefrère F, Rousselot P, Damaj G, Delarue R, Fermand JP, Brouet JC, et al: Phase II trial of arsenic trioxide and alpha interferon in patients with relapsed/refractory adult T-cell leukemia/lymphoma. Hematol J 5: 130-134, 2004.

45. Kchour G, Rezaee R, Farid R, Ghantous A, Rafatpanah H, Tarhini M, Kooshyar MM, El Haij H, Berry F, Mortada M, et al: The combination of arsenic, interferon-alpha and zidovudine restores an 'immunocompetent-like' cytokine expression profile in patients with adult T-cell leukemia lymphoma. Retrovirology 10: 91, 2013.

46. Li Y, Geng S, Du X, Chen S, Yang L, Wu X, Li B, Schmidt CA and Przybylski GK: Restricted TRBV repertoire in CD4+ and CD8+ T-cell subsets from CML patients. Hematology 16: 43-49, 2011.

47. Shi L, Chen S, Yang L and Li Y: The role of PD-1 and PD-L1 in T-cell immune suppression in patients with hematological malignancies. J Hematol Oncol 6: 74, 2013.

48. Yawalkar N, Ferenczi K, Jones DA, Yamanaka K, Suh KY, Sadat S and Kupper TS: Prof-ound loss of T-cell receptor repertoire complexity in cutaneous T-cell lymphoma. Blood 102: 4059-4066, 2003.

49. Eyrich M, Wiegering V, Lim A, Schrauder A, Winkler B and Schlegel PG: Immune function in children under chemotherapy for standard risk acute lymphoblastic leukaemia-a prospective study of 20 paediatric patients. Br J Haematol 147: 360-370, 2009.

50. Zha X, Chen S, Yang L, Li B, Chen Y, Yan X and Li Y: Characterization of the CDR3 structure of the V $\beta 21 \mathrm{~T}$ cell clone in patients with P210 (BCR-ABL)-positive chronic myeloid leukemia and B-cell acute lymphoblastic leukemia. Hum Immunol 72: 798-804, 2011. 